\title{
Antiphospholipid antibodies in localized scleroderma: the potential role of screening tests for the detection of antiphospholipid syndrome
}

\author{
Anna Lis-Święty, Ligia Brzezińska-Wcisło, Hubert Arasiewicz, Beata Bergler-Czop
}

Department of Dermatology, Medical University of Silesia, Katowice, Poland

Head of Department: Prof. Ligia Brzezińska-Wcisło MD, PhD

Postep Derm Alergol 2014; XXXI, 2: 65-70 DOI: $10.5114 /$ pdia.2014.40978

\begin{abstract}
Introduction: The presence of antiphospholipid antibodies (aPL) is associated with infections, drugs and autoimmune disorders. Those antibodies are also detected in approximately 5-20\% of the healthy population. The presence of aPL can lead to the occurrence of thrombotic events or abortion, which define the antiphospholipid syndrome (APS).

Aim: To evaluate the potential role of aPL in diagnosing APS in patients with localized scleroderma (LoS).

Material and methods: Serum samples from 45 patients with various forms of LoS were examined. They were screened with the commercially-available immunodot assay Anti-Phospholipid 10 Dot (GA Generic Assays GmbH, Dahlewitz, Germany). A number of clinical and laboratory parameters, especially APS symptoms, were assessed in patients with positive aPL: arterial and venous thrombotic events, obstetric complications, thrombocytopenia and neurological symptoms.

Results: The following profile of aPL IgG or IgM was obtained from patients with LoS: cardiolipin 15/45, phosphatidic acid 41/45, phosphatidyl-choline $0 / 45$, -ethanolamine $6 / 45$, -glycerole $1 / 45$ (patient with Lyme disease), -inositol $7 / 45$, -serine $14 / 45$, annexin $\vee 34 / 45, \beta 2 \mathrm{GPI} 21 / 45$, prothrombin 30/45. Antiphospholipid antibodies profile screening in these individuals revealed two cases of suspected secondary laboratory APS. However, no such clinical and laboratory parameters were found in other LoS patients with positive aPL. Similarly, no association was found between the presence of aPL and either thrombotic events or other APS symptoms.

Conclusions: Antiphospholipid antibodies are commonly found in patients with LoS but the exact role of these antibodies remains unclear. Clinical manifestations of APS are not frequently seen during LoS.
\end{abstract}

Key words: localized scleroderma, antiphospholipid antibodies, antiphospholipid syndrome.

\section{Introduction}

Localized scleroderma (LOS) is a rare disease, which manifests itself as sclerotic or atrophic skin lesions, but which leaves the internal organs unaffected. Localized scleroderma affects mostly young females around 2040 years old [1]. Different subtypes of the disease can be distinguished depending on the clinical character of the skin lesions: generalized, linear and plaque LoS. The most common form in adults is plaque LoS [1], the first symptom of which is an erythemic blotch, which spreads distally, before fading in its central part and being replaced by hard wax-yellow colored lamina, which is initially surrounded by a lilac ring. The lesions do not tend to disappear but are more likely to become atrophic with hypo- or hyperpigmentation. There are usually sev- eral round to oval lesions of varying sizes and with sharp regular borders, and are typically found on the trunk and lower extremities.

The etiology of LoS is often unknown. Sclerotic lesions appear on intact skin, but can also occur as a result of mechanical damage, radiation therapy or virus infection (Epstein-Barr virus, herpes simplex type 1, varicella zoster, measles, certain human endogenous retroviruses) and after vaccination against tuberculosis, tetanus or tick bites (Borrelia burgdorferi infection) [2-5]. Reports exist about more than one case of LoS within a single family, which suggests that genetic factors play a role in its incidence [6]. Also, its coexistence with other autoimmune diseases suggests that a similar mechanism [2], and numerous autoantibodies have been associated with LoS,

Address for correspondence: Anna Lis-Święty MD, PhD, Department of Dermatology, Medical University of Silesia, 20/24 Francuska St, 40-027 Katowice, Poland, phone: +48 602720 948, e-mail: annadlis@neostrada.pl

Received: 14.11.2013, accepted: 25.01.2014. 
including antinuclear, anti-histone, and anti-ssDNA antibodies [7]. However, the clinical significance of autoantibody testing in scleroderma is unclear, as no association has been found between the presence of any autoantibody and disease activity. Although the anti-histone and ssDNA antibodies may be useful as markers of disease severity in linear LoS, they are not associated with disease activity and are of limited clinical value due to their rarity [7].

Hence, there is a need for studies to identify new biomarkers in LoS. Recent reports note the presence of antiphospholipid antibodies (aPL) in as many as $70 \%$ of patients with LoS [7-10]. However, reports on the prevalence of antiphospholipid syndrome (APS) in patients with LoS are very rare $[11,12]$.

\section{Aim}

The aim of this study was to investigate the risk of developing APS among patients with localized scleroderma by screening them for the presence of $\mathrm{aPL}$.

\section{Material and methods}

The study included 45 patients with LoS (41 women, 4 men) aged 21 to 76 years old, mean age $51.1 \pm 13.5$ years. The duration of the disease was found to range from 12 months to 24 years: on average $5.53 \pm 5.6$. In 22 patients, the first sclerotic skin lesion appeared less than 3 years before being included into the study. All patients were in the active phase of the disease, and the time from the onset of the most recent sclerotic lesion was no longer than 3 years.

The following clinical subtypes of LoS were identified in the patients: 11 plaque, 30 generalized and 4 with linear LoS. A general examination was performed on each patient, as well as a number of laboratory tests including erythrocyte sedimentation rate (ESR), C-reactive protein (CRP), full blood count, liver and kidney function tests, urinalysis and muscle enzyme tests were performed. In addition, the presence of rheumatoid factor, antinuclear antibodies (IF) and antibodies to Borrelia burgdorferi IgM and IgG (ELISA) was measured and nailfold capillaroscopy was performed.

Antibodies to phospholipids and serum proteins in patient serum were detected using the commercially available immunodot assay Anti-Phospholipid 10 Dot (GA Generic Assays GmbH, Dahlewitz, Germany), which is used for the qualitative detection of IgG or IgM antibodies reacting to a highly purified antigen preparation comprising cardiolipin, phosphatidic acid, phosphatidyl-choline, -ethanolamine, -glycerole, -inositol, -serine, annexin V, $\beta 2$-glycoprotein I ( $\beta 2 \mathrm{GPI}$ ) and prothrombin. The assessment of aPL was conducted according to the manufacturer's instructions.
The intensity of the bands given on the evaluation template served as a cut-off value to determine whether each single band was positive or negative. Sera were considered to be positive with respect to one of the antibodies if the coloration of the test line was more intense than that of the band on the evaluation template. Alternatively, sera were considered to be negative with respect to one of the antibodies if the coloration of the test line was equally or less intense than that of the band on the evaluation template. In order to interpret the results, the test line of the positive control had to show a clear coloration. According to the manufacturer, although the Anti-Phospholipid 10 Dot should give a negative result in healthy individuals, asymptomatic individuals can show a positive antibody reaction. The evaluation of antibodies against phospholipids was performed twice, according to the APS diagnosis requirements.

Patients found to be positive for aPL were assessed with regard to a number of clinical and laboratory parameters, especially symptoms of APS: arterial and venous thrombotic events, obstetric complications, thrombocytopenia and neurological symptoms.

\section{Statistical analysis}

The relationship between the presence of aPL and the studied clinical features was expressed by correlation coefficients, and their statistical significance. All statistical analyses were performed with Excel and Statistica 9.0.

\section{Results}

Table 1 shows the clinical characteristics of $45 \mathrm{pa}$ tients with various forms of LoS as well as the aPL profile of their serum samples. Of these 45 patients, skin lesions were found to most commonly occur on the trunk (38 patients), followed by the lower extremities (29 patients), upper extremities (18 patients) and neck (4 patients). Inflammatory lesions with erythematous patches and a lilac ring were observed in 27 patients, sclerotic lesions were present in 37, and atrophic lesions in 35 patients.

In 11 cases, skin lesions were accompanied by pain in joints and muscles, and muscle weakness was noted in 6. Five patients reported a history of thrombosis, 7 patients miscarriages, 3 patients a strong headache, and 2 patients reported problems with vision due to vascular complications. Arterial hypertension was found in 16 cases. Four patients reported a history of cigarette smoking.

No significant abnormalities were noted in the following laboratory tests: ESR, CRP, full blood count, liver and kidney function tests, muscle enzymes. Rheumatoid factor was detected in 2 patients, antinuclear antibodies in 9, antibodies against Borrelia burgdorferi lgM and/ or IgG in 4 patients: one of whom was diagnosed with Lyme disease while the other 3 were asymptomatic at the moment of the study and their anamnesis was found 
Table 1. Clinical characteristics and the aPL profile in serum samples from 45 patients with various forms of localized scleroderma

\begin{tabular}{|c|c|c|c|c|c|c|c|c|c|c|c|}
\hline \multirow[t]{2}{*}{$\begin{array}{l}\text { Characteristics of patients } \\
(n=45)\end{array}$} & & $\begin{array}{l}\text { Cardio- } \\
\text { lipin }\end{array}$ & $\begin{array}{l}\text { Phospha- } \\
\text { tidic } \\
\text { acid }\end{array}$ & $\begin{array}{l}\text { Phospha- } \\
\text { tidyl- } \\
\text { choline }\end{array}$ & $\begin{array}{l}\text {-ethano- } \\
\text { lamine }\end{array}$ & $\begin{array}{l}\text {-gly- } \\
\text { cerol }\end{array}$ & $\begin{array}{l}\text {-ino- } \\
\text { sitol }\end{array}$ & $\begin{array}{l}- \text { se- } \\
\text { rine }\end{array}$ & $\begin{array}{l}\text { Anne- } \\
\text { xin V }\end{array}$ & $\beta 2 \mathrm{GPI}$ & $\begin{array}{l}\text { Prothrom- } \\
\text { bin }\end{array}$ \\
\hline & & 15 & 41 & 0 & 6 & 1 & 7 & 14 & 34 & 21 & 30 \\
\hline $\begin{array}{l}\text { The onset of skin lesions } \\
\text { less than } 3 \text { years }\end{array}$ & 22 & 8 & 20 & 0 & 4 & 0 & 3 & 7 & 16 & 9 & 15 \\
\hline $\begin{array}{l}\text { The onset of skin lesions } \\
\text { more than } 3 \text { years }\end{array}$ & 23 & 5 & 22 & 0 & 2 & 0 & 2 & 7 & 10 & 10 & 15 \\
\hline Plaque scleroderma & 21 & 8 & 19 & 0 & 3 & 0 & 5 & 6 & 16 & 11 & 13 \\
\hline Generalized scleroderma & 30 & 9 & 28 & 0 & 4 & 1 & 4 & 8 & 22 & 15 & 20 \\
\hline Linear scleroderma & 4 & 0 & 3 & 0 & 3 & 0 & 0 & 1 & 3 & 2 & 3 \\
\hline Skin lesions on the trunk & 38 & 14 & 35 & 0 & 4 & 1 & 7 & 12 & 29 & 18 & 26 \\
\hline $\begin{array}{l}\text { Skin lesions on the lower } \\
\text { extremities }\end{array}$ & 29 & 11 & 28 & 0 & 3 & 1 & 3 & 9 & 23 & 15 & 20 \\
\hline $\begin{array}{l}\text { Other localization of skin } \\
\text { lesions }\end{array}$ & 20 & 7 & 20 & 0 & 1 & 1 & 2 & 7 & 15 & 10 & 14 \\
\hline Inflammatory skin lesions & 27 & 7 & 25 & 0 & 3 & 0 & 3 & 11 & 20 & 14 & 18 \\
\hline Sclerotic skin lesions & 37 & 12 & 33 & 0 & 6 & 1 & 6 & 13 & 29 & 17 & 25 \\
\hline Atrophic skin lesions & 35 & 9 & 33 & 0 & 4 & 1 & 6 & 11 & 27 & 17 & 24 \\
\hline $\begin{array}{l}\text { Pain in joints and/or } \\
\text { muscles }\end{array}$ & 11 & 6 & 11 & 0 & 2 & 1 & 2 & 5 & 10 & 5 & 8 \\
\hline Arterial hypertension & 16 & 7 & 15 & 0 & 2 & 0 & 2 & 7 & 13 & 10 & 11 \\
\hline $\begin{array}{l}\text { Venous or arterial } \\
\text { thrombosis }\end{array}$ & 5 & 1 & 4 & 0 & 0 & 0 & 1 & 3 & 4 & 3 & 3 \\
\hline Pregnancy complication & 7 & 2 & 7 & 0 & 2 & 0 & 2 & 1 & 5 & 2 & 3 \\
\hline Rheumatoid factor (RF) & 2 & 1 & 1 & 0 & 0 & 0 & 0 & 0 & 1 & 0 & 1 \\
\hline $\begin{array}{l}\text { Antinuclear antibodies } \\
\text { (ANA) }\end{array}$ & 9 & 5 & 9 & 0 & 4 & 0 & 1 & 2 & 6 & 2 & 7 \\
\hline $\begin{array}{l}\text { Anti-Borrelia burgdorferi } \\
\text { antibodies }\end{array}$ & 4 & 1 & 3 & 0 & 1 & 0 & 2 & 0 & 4 & 2 & 3 \\
\hline $\begin{array}{l}\text { Abnormalities in nailfold } \\
\text { capillaroscopy }\end{array}$ & 12 & 4 & 11 & 0 & 0 & 0 & 2 & 5 & 11 & 5 & 9 \\
\hline
\end{tabular}

to be free of Lyme disease. Capillaroscopy revealed uncharacteristic changes in nailfold flow in 12 patients. The following aPL IgG or IgM profile was obtained: cardiolipin in 15 of the 45 patients, phosphatidic acid 41/45, phosphatidyl-choline 0/45, -ethanolamine 6/45, -glycerol 1/45 (patient with Lyme disease), -inositol 7/45, -serine 14/45, annexin V 34/45, $\beta 2 \mathrm{GPI} 21 / 45$, and prothrombin 30/45.

No correlation was found between the presence of aPL and clinical features of LoS, variations in laboratory tests or nailfold capillaroscopy given above. Two patients in whom a positive medical history of venous or arterial thrombosis was found and were positive for $\beta 2 \mathrm{GPI}$ antibodies are still under observation for APS. In 1 of these patients, 57 years old, two brain infarcts had been reported before the start of the study. The first in- farct, which occurred 3 years before this investigation, occurred 6 months before the first sclerotic skin lesion appeared on the trunk of the patient, followed by a gradual progression of sclerotic lesions. A significant increase and generalization of sclerotic lesions was observed at the time of the present study, which was 6 months after the second stroke. The second patient, 58 years old, underwent venous thrombosis of the lower limbs. The first sclerotic lesions appeared on the lower extremities 10 weeks after the administration of low molecular weight heparin. Eight months before the start of the study there was a generalization of skin lesions (Figures 1 A-D). In both patients, PUVA phototherapy and SUP 311 were used in the treatment of LoS. Aspirin was recommended to both patients for antithrombotic prophylaxis. 

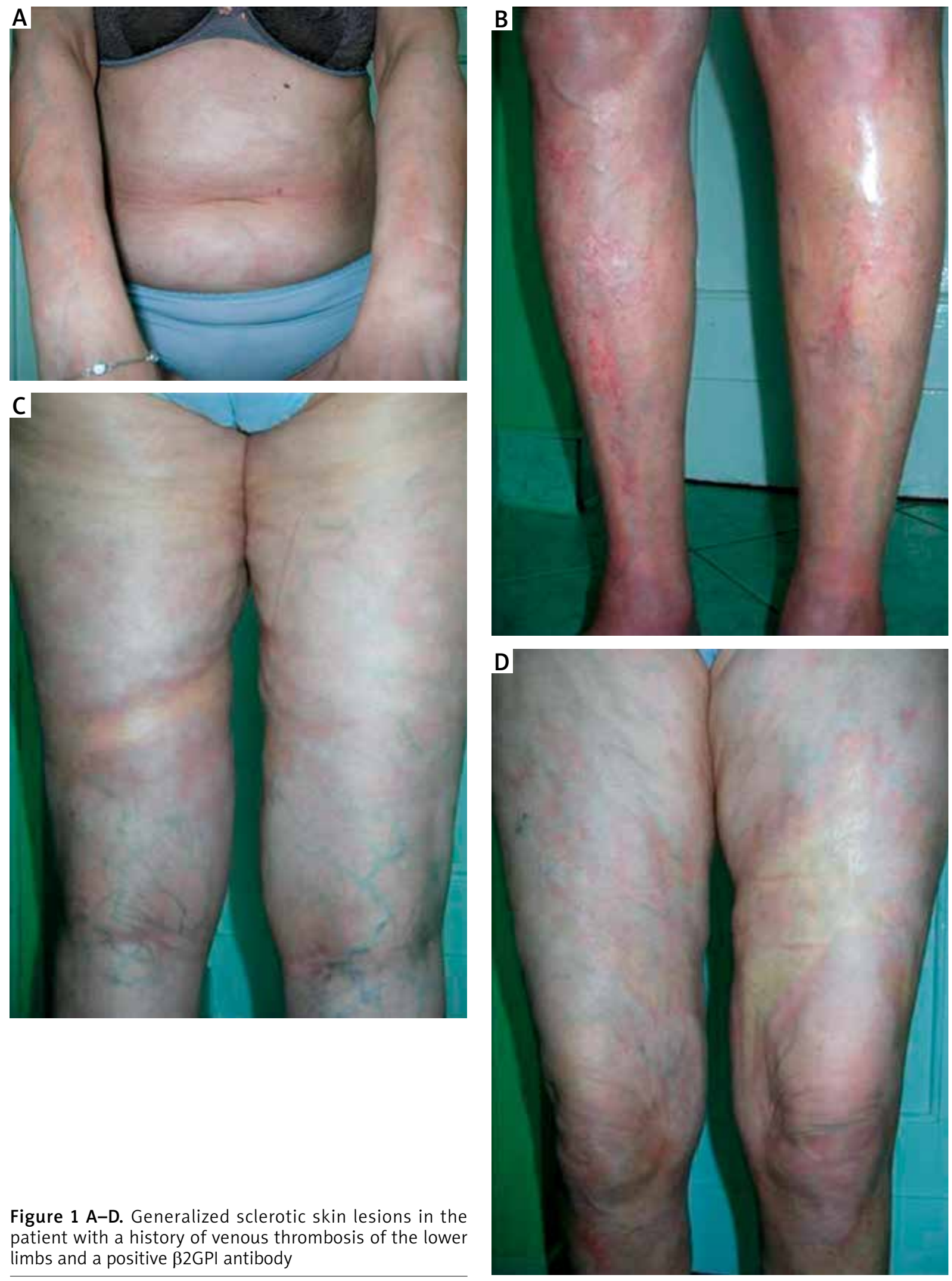

Figure $1 \mathrm{~A}-\mathrm{D}$. Generalized sclerotic skin lesions in the patient with a history of venous thrombosis of the lower limbs and a positive $\beta 2 \mathrm{GPI}$ antibody 
No other patients in the study showed an association between clinical signs such as a history of thrombosis, fetal loss or other symptoms, and the presence of $\mathrm{aPL}$ IgG or IgM. Similarly, no association was found between the impact of cigarette smoking and the prevalence of these antibodies.

\section{Discussion}

Antiphospholipid antibodies are a heterogeneous group of autoantibodies that can bind directly to phospholipids, thus allowing them to exert an influence on protein cofactors or complexes containing phospholipids. The presence of $\mathrm{aPLS}$, which react only with pure phospholipids, is very often naturally associated with some infections, the most common of which are syphilis and Lyme disease [13]. In addition, aPL positivity can be triggered by EBV, CMV, HIV, and hepatitis C virus [13]. Sensitive diagnostic methods such as ELISA have revealed that aPLS are present in approximately $5-20 \%$ of the healthy population $[13,14]$, and are found in low titers in nearly $75 \%$ of patients taking certain medications: chlorpromazine, phenytoin, hydralazine, procainamide, quinidine, streptomycin and some hormonal contraceptives [13].

However, about $30-50 \%$ of patients with positive aPL suffer from episodes of thrombosis and/or miscarriages, which define the "antiphospholipid syndrome" (APS) [15]. Two types of APS can be distinguished: primary APS, which is unaccompanied by any other related disease and experienced by around 62\% of patients, and secondary APS, which is usually associated with systemic lupus erythematosus (SLE) [15]. Clinically, primary and secondary APS are indistinguishable. The diagnostic criteria require one clinical event and at least one positive serological test. Symptoms should be reported not less than 12 weeks and not longer than 5 years after the detection of antibodies [16]. Clinical criteria include: 1 . Venous or arterial thrombosis confirmed by imaging methods such as ultrasonography, or by microscopic examination only when the inflammatory process does not affect the vessel wall; 2. Obstetric failure in the form of (a) one or more unexplained death of a morphologically normal fetus during the first 10 weeks of pregnancy, or (b) one or more premature births of morphologically normal neonates before the $34^{\text {th }}$ week of pregnancy due to eclampsia, severe pre-eclampsia or placental insufficiency; (c) three or more consecutive spontaneous abortions before the $10^{\text {th }}$ week of pregnancy, after exclusion of anatomical or hormonal causes of maternal and chromosomal aberrations in both parents.

The laboratory criteria for APS include elevated titers of anticardiolipin antibodies ( $\mathrm{aCL}$ ), presence of antibodies against $\beta 2 \mathrm{GPI}$ or the presence of lupus anticoagulant (LAC). Positive laboratory tests should be confirmed twice and performed at an interval of at least 12 weeks. In addition to these clinical criteria, aPL may be a cause of thrombocytopenia, anemia and skin lesions in the form of livedo reticularis, ulcers or anetoderma [15-18]. The presence of aPL may be accompanied by some other symptoms not specific to APS like blurred vision, hearing disorders, nephropathy or changes in the heart valves $[15,17]$.

Although aPL are largely directed against $\beta 2 \mathrm{GPI}$, prothrombin and/or cardiolipin, new antigenic targets for aPL in APS syndrome have been investigated recently [19]. The most common epitopes against which aPL antibodies react are phosphatidic acid, phosphatidyl ethanolamine, phosphatidyl-DL-glycerol, phosphatidylinositol, phosphatidyl-L-serine and annexin V [19]. Sato et al. [9] showed that while anti-cardiolipin antibody (IgG or IgM) and lupus anticoagulant are frequently detected in LoS patients at the frequency of $46 \%$ and $24 \%$, respectively, anti- $\beta 2 \mathrm{GPI}$ antibodies were not found to be present in their patients. The same authors noted that the frequency of IgG anti-phosphatidylserine-prothrombin complex antibodies in generalized morphea (27\%) was comparable with that in systemic lupus erythematosus (32\%), and reported symptomatic thromboembolism in 2 patients with generalized morphea with anti-phosphatidylserine-prothrombin complex antibodies [11]. Antibodies against phosphatidylserine-prothrombin complex have elsewhere been shown to be significantly associated with clinical manifestations of APS [20].

In the present study involving 45 patients with LoS, in cases, episodes of thrombosis associated with the presence of antibodies against $\beta 2 \mathrm{GPI}$ were reported. In both patients, thrombotic episodes were linked to development of sclerotic skin lesions and their progression. However, the interpretation of the significance of aPL in LoS is difficult. Other patients with positive aPL antibodies did not show any symptoms suggestive of APS development. Furthermore, the presence of aPL was not found to correlate with clinical features such as duration of the disease, its character, location or nature of skin lesions, presence of pain in joints and muscles or immune disorders.

Antibodies regarded as the most important in the diagnosis of APS were found to be relatively common in the study LoS group: anti- $\beta 2 \mathrm{GPI} 21 / 45 \mathrm{Ab}$ and anti-cardiolipin (15/45). However, antibodies against phosphatidic acid (41/45), annexin V (34/45) and prothrombin (30/45) were more common and those against phosphatidyl-serine (14/45) were rarer. Antibodies to phosphatidylinositol (7/45), phosphatidyl ethanolamine (6/45) and phosphatidyl-DL-glycerol (1/45) were rare and antibodies against phosphatidyl-choline were not detected in any patients' serum. It has been shown that antibodies against lyso(bis)phosphatidic acid (aLBPA) may represent a marker of APS, showing similar sensitivity and specificity as anti- $\beta 2 \mathrm{GPI}$ and are associated strongly with the presence of LAC [21]. Antibodies to annexin V have been identified in association with several pathological conditions, in- 
cluding SLE, undifferentiated connective tissue disease, rheumatoid arthritis, Sjögren's syndrome and systemic sclerosis (SSc), with or without APS or recurrent spontaneous abortions [22]. Measurement of serum anti-annexin V IgG antibodies in SSc patients may be important for early diagnosis of vascular and pulmonary complications [23].

However, the clinical significance of the anti-prothrombin antibody, responsible for the presence of $L A C$, is still a matter of debate. In arterial thrombosis, anti-phosphatidylserine antibodies were reported to be better correlated with APS than anticardiolipin antibodies [14]. Anti-phosphatidylserine and anti-phosphatidylinositol antibodies are regarded as markers for cerebral diseases and recurrent miscarriages [24]. Anti-phosphatidylethanolamine antibodies are frequently seen in SLE (41\%) and do not correlate with other routinely tested aPLS [25]. Although more prevalent, anti-phosphatidylethanolamine is not an independent risk factor for thrombosis or pregnancy morbidity in patients with SLE [25]. The role of these antibodies in individuals with unexplained thrombosis and pregnancy morbidity remains intriguing [26].

\section{Conclusions}

Antiphospholipid antibodies are commonly found in patients with LoS but the "typical" clinical manifestations of APS are not frequently seen in these patients. Further studies are required to assess the exact role of these aPLS during LoS.

\section{Conflict of interest}

All authors declare no conflict of interest.

\section{References}

1. Leitenberger JJ, Cayce RL, Haley RW. Distinct autoimmune syndromes in morphea: a review of 245 adults and pediatric cases. Arch Dermatol 2009; 145: 545-50.

2. Zulian F, Athreya BH, Laxer R, et al. Juvenile localized scleroderma: clinical and epidemiological features in 750 children. An international study. Rheumatology 2006; 45: 614-20.

3. Dańczak-Pazdrowska A, Kowalczyk MJ, Szramka-Pawlak B, et al. Transforming growth factor-beta1 in plaque morphea. Postep Derm Alergol 2013; 30: 337-42.

4. Lipko-Godlewska S, Wojas-Pelc A. INF-gamma serum level in patients with morphoea and atrophoderma Pasini-Pierini considering clinical activity of disease. Postep Derm Alergol 2008; 25: 214-9.

5. Kowalczyk MJ, Dańczak-Pazdrowska A, Szramka-Pawlak B, et al. Expression of selected human endogenous retroviral sequences in skin and peripheral blood mononuclear cells in morphea. Arch Med Sci 2012; 8: 819-25.

6. Jabłońska S. Familial occurrence of scleroderma. J Eur Acad Dermatol Venereol 2010; 15: 9-10.

7. Nouri S, Jacobe H. Recent developments in diagnosis and assessment of morphea. Curr Rheumatol Rep 2013; 15: 308.
8. Castanet J, Lacour JP, Perrin C, et al. Association of eosinophilic fasciitis, multiple morphea and antiphospholipid antibody. Dermatology 1994; 189: 304-7.

9. Sato S, Fujimoto M, Hasegawa M, Takehara K. Antiphospholipid antibody in localised scleroderma. Ann Rheum Dis 2003; 62: 771-4.

10. Takehara K, Sato S. Localized scleroderma is an autoimmune disorder. Rheumatology (Oxford) 2005; 44: 274-9.

11. Hasegawa M, Fujimoto M, Hayakawa I, et al. Anti-phosphatidylserine-prothrombin complex antibodies in patients with localized scleroderma. Clin Exp Rheumatol 2006; 24: 19-24.

12. Lago H, Grinberg A. Lineal scleroderma, spontaneous abortion and hemiplegia: pulmonary hemorrhage, antiphospholipid antibodies and angiocentric lymphoma. Medicina (B Aires) 1998; 58: 67-77.

13. Horstman LL, Jy W, Bidot CJ, et al. Antiphospholipid antibodies: paradigm in transition. J Neuroinflammation 2009; 6: 3 .

14. Rand JH, Wolgast LR. Dos and don'ts in diagnosing antiphospholipid syndrome. Hematology Am Soc Hematol Educ Program 2012; 2012: 455-9.

15. Nayfe R, Uthman I, Aoun J, et al. Seronegative antiphospholipid syndrome. Rheumatology (Oxford) 2013; 52: 1358-67.

16. Szturmowicz M. Antiphospholipid syndrome - an update on diagnosis and treatment [Polish]. Pneumonol Alergol Pol 2009; 77: 460-8.

17. Gerkowicz A, Chodorowska G, Michalak-Stoma A, et al. Antiphospholipid syndrome - clinical manifestation, diagnostics and literature review. Postep Derm Alergol 2010; 27: 69-75.

18. Lis-Święty A, Brzezińska-Wcisło L, Trzmiel D, Szynol-Woźniak B. Anetodermia - a predictor of the occurrence of systemic involvement [Polish]. Przegl Dermatol 2004; 91: 487-90.

19. Egerer K, Roggenbuck D, Büttner T, et al. Single-step autoantibody profiling in antiphospholipid syndrome using a multiline dot assay. Arthritis Res Ther 2011; 13: R118.

20. Pregnolato F, Chighizola CB, Encabo S, et al. Anti-phosphatidylserine/prothrombin antibodies: an additional diagnostic marker for APS? Immunol Res 2013; 56: 432.

21. Alessandri C, Bombardieri M, Di Prospero L, et al. Anti-lysobisphosphatidic acid antibodies in patients with anti-phospholipid syndrome and systemic lupus erythematosus. Clin Exp Immunol 2005; 140: 173-80.

22. Iaccarino L, Ghirardello A, Canova M, et al. Anti-annexins autoantibodies: their role as biomarkers of autoimmune diseases. Autoimmun Rev 2011; 10: 553-8.

23. El Serougy IM, Shahin AA, Soliman DA, et al. Clinical significance of serum anti-annexin $\mathrm{V}$ antibodies in Egyptian patients with scleroderma. Egypt I Immunol 2009; 16: 1-8.

24. Faricelli R, Esposito S, Toniato E, et al. A new diagnostic approach to better identify antiphospholipid syndrome. Int J Immunopathol Pharmacol 2008; 21: 387-92.

25. Bertolaccini ML, Murru V, Sciascia S, et al. The clinical value of testing for antibodies to phosphatidylethanolamine (aPE) in patients with systemic lupus erythematosus (SLE). Thromb Res 2012; 130: 914-8.

26. Staub HL, Bertolaccini ML, Khamashta MA. Anti-phosphatidylethanolamine antibody, thromboembolic events and the antiphospholipid syndrome. Autoimmun Rev 2012; 12: 230-4. 